\title{
Jurnal Manajemen dan Bisnis
}

Vol. 8, No. 2, Desember 2019, pp. 328-341

\section{Sekolah Tinggi Ilmu Ekonomi Indragiri (STIE-I) Rengat}

P-ISSN : 2302-4313 P-ISSN : $2302-4313$

http://journal.stieindragiri.ac.id/index.php/jmbi

\section{FAKTOR - FAKTOR YANG MEMPENGARUHI KEPUTUSAN PEMBELIAN DAN DAMPAKNYA PADA KELANGSUNGAN USAHA MIKRO KECIL MENENGAH PADA USAHA FOTOCOPY SEKECAMATAN RENGAT}

\author{
Hermanto $^{1)}$ Fatti Corrina $^{2)}$ Agus Supriyadi $^{3)}$ \\ 1) 2) 3) Program Studi Manajemen, Sekolah Tinggi Ilmu Ekonomi Indragiri (STIE-I) Rengat \\ Jl. R. Soeprapto No. 14. Rengat | Telp. (0769) 21019 | Kode Pos : 29312 | Inhu, Riau \\ ${ }^{1)}$ hermanto@stieindragiri.ac.id ${ }^{2)}$ fatticorrina@stieindragiri.ac.id ${ }^{3)}$ agussupriyadi@stieindragiri.ac.id \\ Submited: 2019.10.17 Reviewed: 2019.10.28 Accepted: 2019.11.14 \\ https://doi.org/10.34006/jmbi.v8i2.131
}

\begin{abstract}
This research was conducted at Micro, Small and Medium Enterprises engaged in the Photocopy business in Rengat District. The sample in this study were consumers who shop at a copy of Rengat District as many as 270 samples. The type of data used in this study is primary data in the form of quantitative data conducted by distributing consumer questionnaires who shop. The analytical tool used by the author is Multiple Linear Regression Analysis with a quantitative approach with the help of SPSS Software Version 21. The results of the study can be concluded that: (1) The product partially has a significant effect on Purchasing Decisions in a Photocopy business in Rengat District. (2) Price partially has a significant effect on Purchasing Decisions in a Photocopy business in Rengat District. (3) Location partially has a significant effect on Purchasing Decision in a Photocopy business in Rengat District. (4) Promotion partially has a significant effect on Purchasing Decisions in a Photocopy business in Rengat District. (5) Product, Price, Location and Promotion simultaneously has a significant effect on the Purchasing Decision in a Photocopy business in Rengat District.
\end{abstract}

Keywords: Product, Price, Location, Promotion and Purchase Decision

\begin{abstract}
Abstrak
Penelitian ini dilakukan pada Usaha Mikro, Kecil dan Menengah yang bergerak di usaha Fotocopy pada Kecamatan Rengat. Sampel dalam penelitian ini adalah konsumen yang berbelanja di Fotocopy yang ada dikecamatan Rengat sebanyak 270 Sampel. Jenis data yang digunakan dalam penelitian ini adalah data primer yaitu berupa data kuantitatif yang dilakukan dengan menyebarkan kuisioner kekonsumen yang berbelanja. Alat analisis yang penulis gunakan ialah Analisis Regresi Linear Berganda dengan pendekatan kuantitatif dengan bantuan Software SPSS Versi 21. Hasil penelitian dapat disimpulkan bahwa : (1) Produk secara parsial berpengaruh signifikan terhadap Keputusan Pembelian pada usaha Fotocopy seKecamatan Rengat. (2) Harga secara parsial berpengaruh signifikan terhadap Keputusan Pembelian pada usaha Fotocopy seKecamatan Rengat. (3) Lokasi secara parsial berpengaruh signifikan terhadap Keputusan Pembelian pada usaha Fotocopy seKecamatan Rengat. (4) Promosi secara parsial berpengaruh signifikan terhadap Keputusan Pembelian pada usaha Fotocopy seKecamatan Rengat. (5) Produk, Harga, Lokasi dan Promosi secara simultan berpengaruh signifikan terhadap Keputusan Pembelian pada usaha Fotocopy seKecamatan Rengat.
\end{abstract}

Kata Kunci : Produk, Harga, Lokasi, Promosi dan Keputusan Pembelian

\section{PENDAHULUAN}

Dalam perkembangan zaman yang semakin meningkat, banyak usaha baru yang muncul baik yang kecil sampai yang besar. Sebagai pelaku usaha harus mampu bertahan dengan kondisi seperti itu. Dengan kemajuan tekonologi yang sekarang ini serba canggih, pelaku usaha harus juga mampu menangkap peluang yang ada pada saat ini. Diindonesia ini banyak UMKM yang tumbuh dari tahun sebelumnya. Dapat dilihat dari pernyataan Menteri Koperasi dan Usaha Kecil Menengah Agung Gede Ngurah Puspayoga bahwa persentase UMKM di Indonesia sudah meningkat signifikan dan menembus "batas psikologis" persentase UMKM kategori Negara maju yang sebesar $2 \%$ menjadi kabar yang menggembirakan. Dari hanya $1,67 \%$ di 
tahun 2013 / 2014 telah meningkat 3,1\% pada paruh awal tahun 2017. Nasional.sindonews.com.

Kota Rengat merupakan kota yang banyak dijumpai berbagai jenis usaha UMKM, salah satu usaha Fotocopy. Bila dilihat usaha fotocopy ini usaha yang sangat menjanjikan bagi pelaku bisnis, hal ini tentu tidak terlepas dari pengelolaan manajemennya dalam mengelola usahanya. Setiap tahunnya dijumpai pelaku - pelaku usaha fotocopy. Sebagai pelaku usaha agar dapat bertahan, harus mempertimbangkan faktor - faktor yang mempengaruhi keputusan pembelian dari konsumen, karena bila pelaku usaha lalai dengan persaingan yang semakin pesat akan membuat pelaku usaha tutup dalam menjalankan aktivitas usahanya.

Berikut bisa dilihat jenis usaha UMKM seperti Fotocopy yang bertambah setiap tahunnya di Kota Rengat dari tahun 2015 s/d 2018 pada saat ini :

Tabel 1. Jumlah Usaha Fotocopy di Kota Rengat dari tahun 2015 s/d 2018

\begin{tabular}{|c|c|c|}
\hline No & Tahun & Jumlah \\
\hline 1. & 2015 & 28 Pelaku Usaha \\
\hline 2. & 2016 & 35 Pelaku Usaha \\
\hline 3. & 2017 & 41 Pelaku Usaha \\
\hline 4. & 2018 & 49 Pelaku Usaha \\
\hline
\end{tabular}

Sumber : Dinas Perindustrian dan Perdagangan Kabupaten Indragiri Hulu Tahun 2018

Dapat dilihat bahwa setiap tahunnya banyak pelaku usaha yang muncul dalam berbisnis usaha Fotocopy ini, hal ini tidak menutup kemungkinan bagi pelaku usaha untuk melakukan persaingan didalam bisnis, bagaimana para pelaku usaha untuk memenangkan persaingan usaha dengan memperhatikan keputusan pembelian dari konsumen, hal itu berguna bagi kelangsungan hidup usahanya. Berdasarkan uraian diatas maka penulis tertarik mengangkat penelitian mengenai Faktor - Faktor yang mempengaruhi Keputusan Pembelian dan Dampaknya pada Kelangsungan Usaha Mikro Kecil Menengah pada Usaha Fotocopy Sekecamatan Rengat.

\section{TINJAUAN PUSTAKA DAN HIPOTESIS \\ Keputusan Pembelian}

Suatu proses keputusan pembelian bukan sekedar mengetahui berbagai faktor yang akan mempengaruhi pembeli, tetapi berdasarkan peranan dalam pembelian dan keputusan untuk membeli. Terdapat lima peran yang tejadi dalam keputusan membeli : (Simamora, 2008:15)

1. Pemrakarsa (initiator). Orang yang pertama kali menyarankan membeli suatu produk atau jasa tertentu.

2. Pembeli pengaruh (influencer). Orang yang pandangan/nasihatnya memberi bobot dalam pengambilan keputusan akhir.

3. Pengambilan keputusan (decider). Orang yang sangat menentukan sebagian atau keseluruhan keputusan pembelian, apakah membeli, apa yang dibeli, kapan hendak membeli, dengan bagaimana cara membeli dan dimana akan membeli.

4. Pembeli (buyer). Orang yang melakukan pembelian nyata.

5. Pemakai (user). Orang yang mengkosumsi atau menggunakan produk atau jasa..

\section{Produk}

Menurut kotler dalam (Mursid, 2010:71), produk adalah hasil akhir yang mengandung elemen-elemen fisik, jasa dan hal-hal yang simbolis yang dibuat dan dijual oelh perusahaan untuk memberikan kepuasan dan keuntungan bagi pembelinya.

Didalam pemilihan produk yang dijual, seorang pelaku bisnis perlu memperhatikan keanekaragaman produk, kualitas produk, desain produk, bentuk produk, merek produk, kemasan/label, ukuran produk, layanan, jaminan dan pengembalian. 


\section{Harga}

Menurut kotler dalam (Sunyoto, 2014:131), harga adalah sejumlah uang yang dibebankan pada suatu produk tertentu. Dan menurut Indriyo dalam (Sunyoto, 2014:141) ada dua strategi dalam penetapan harga yaitu strategi harga bagi produk baru dan strategi harga bauran produk.

\section{Lokasi}

Menurut assauri (2013:84), lokasi adalah tempat usaha yang sangat mempengaruhi keinginan seseorang konsumen untuk datang dan berbelanja. Ada dua langkah yang harus diperhatikan dalam memilij sebuah lokasi usaha adalah menentukan masyarakat yang akan dituju atau dilayani dan memilih lokasi disekitar masyarakat.

\section{Promosi}

Menurut hamdani dalam (Sunyoto, 2014:154) promosi merupakan salah satu variabel dalam bauran pemasaran yang sangat penting dilaksanakan oleh perusahaan dalam memasarkan produk. Dan menurut Ginting (2011:206) hal-hal yang perlu diperhatikan dalam promosi penjualan itu adalah pertumbuhan cepat, maksud promosi, menentukan tujuan promosi penjualan, memilih alat promosi dan membangun program promosi.

\section{Kerangka Pemikiran}

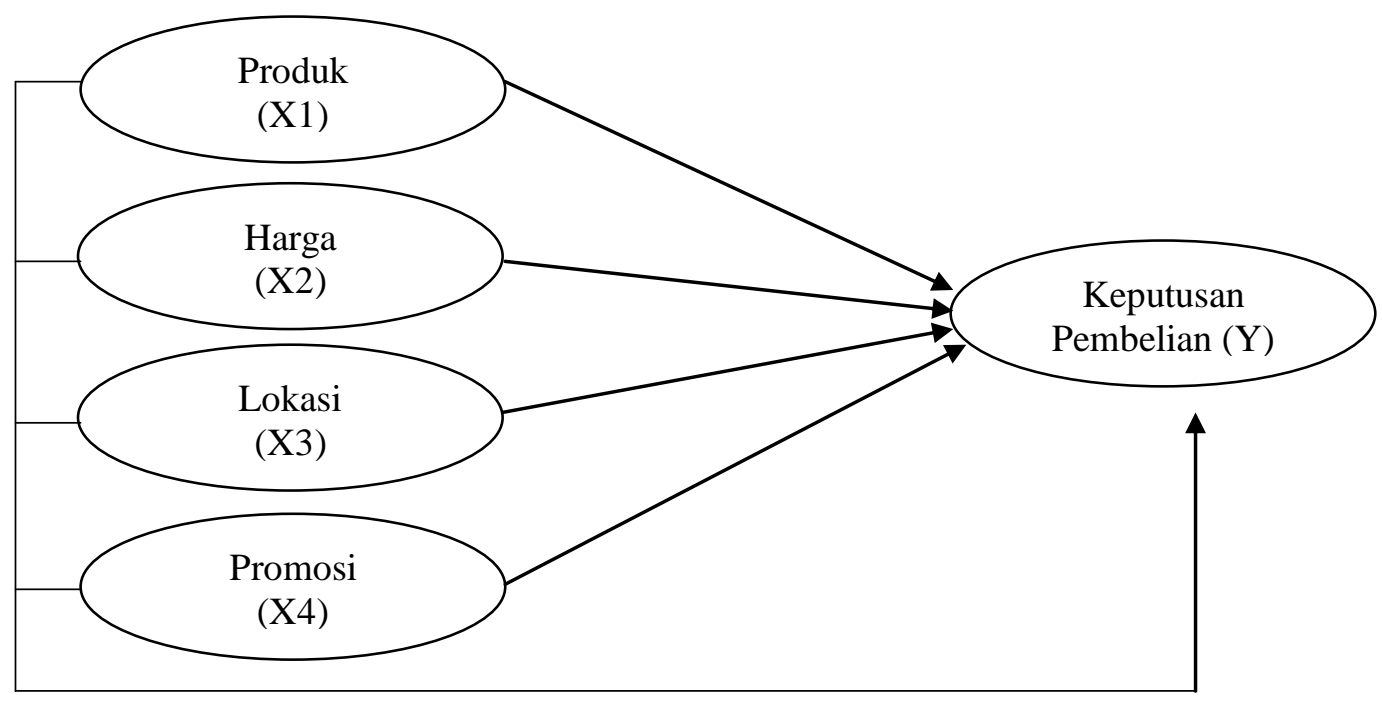

Sumber : Peneliti kembangkan pada Penelitian ini Gambar 1 : Kerangka Berfikir/ Pemikiran 


\section{Hipotesis Penelitian}

Mengacu kepada kerangka pemikiran, penelitian ini memiliki hipotesis yakni sebagai berikut :

1. Apakah Produk, Harga, Lokasi dan Promosi secara simultan berpengaruh terhadap Keputusan Pembelian pada Usaha Fotocopy seKecamatan Rengat.

2. Apakah Produk secara parsial berpengaruh terhadap Keputusan Pembelian pada Usaha Fotocopy seKecamatan Rengat.

3. Apakah Harga secara parsial berpengaruh terhadap Keputusan Pembelian pada Usaha Fotocopy seKecamatan Rengat.

4. Apakah Lokasi secara parsial berpengaruh terhadap Keputusan Pembelian pada Usaha Fotocopy seKecamatan Rengat.

5. Apakah Promosi secara parsial berpengaruh terhadap Keputusan Pembelian pada Usaha Fotocopy seKecamatan Rengat.

\section{METODE PENELITIAN}

Penelitian ini dilakukan di UMKM yang bergerak di bidang jasa Fotocopy Sekecamatan Rengat, Kabupaten Indragiri Hulu, Provinsi Riau dengan pendekatan deskriptif kuantitatif. Populasi dalam penelitian ini adalah konsumen yang berbelanja di seluruh fotocopy kota rengat yang lebih kurang 1800 konsumen. Penentuan sampel menurut pendapat Winarno Surakhmad (2004), “ Apabila ukuran populasi sebanyak kurang lebih 100, maka pengambilan sampel sekurang-kurangnya 50\% dari populasi, dan apabila populasi sama dengan atau diatas 1000 ukuran sampel dapat digunakan sekurang-kurangnya 15\%. Atas dasar teori tersebut pada penelitian ini diperoleh sampel sebanyak : 1800 x $15 \%=270$ sampel. Data dalam penelitian ini adalah data primer, yaitu berupa data angket yang langsung di isi oleh komsumen yang berbelanja. Pengolahan Data data dalam penelitian menggunakan IBM SPSS Versi 21.

\section{HASIL DAN PEMBAHASAN}

1. Uji Instrumen

a. Uji Validitas

Tabel 2. Uji Validitas

\begin{tabular}{|c|c|c|c|}
\hline Pertanyaan & $\mathrm{R}_{\text {hitung }}$ & $\mathrm{R}_{\text {tabel }}$ & Keterangan \\
\hline Produk 1 & 0,712 & 0,1194 & Valid \\
\hline Produk 2 & 0,742 & 0,1194 & Valid \\
\hline Produk 3 & 0,705 & 0,1194 & Valid \\
\hline Harga 1 & 0,655 & 0,1194 & Valid \\
\hline Harga 2 & 0,700 & 0,1194 & Valid \\
\hline Harga 3 & 0,749 & 0,1194 & Valid \\
\hline Lokasi 1 & 0,621 & 0,1194 & Valid \\
\hline Lokasi 2 & 0,749 & 0,1194 & Valid \\
\hline Lokasi 3 & 0,740 & 0,1194 & Valid \\
\hline Promosi 1 & 0,759 & 0,1194 & Valid \\
\hline Promosi 2 & 0,801 & 0,1194 & Valid \\
\hline Promosi 3 & 0,704 & 0,1194 & Valid \\
\hline Keputusan Pembelian 1 & 0,736 & 0,1194 & Valid \\
\hline Keputusan Pembelian 2 & 0,727 & 0,1194 & Valid \\
\hline Keputusan Pembelian 3 & 0,692 & 0,1194 & Valid \\
\hline
\end{tabular}


Berdasarkan hasil pengujian validitas dideperoleh semua $R_{\text {hitung }}$ dari kuisioner yang ditanyakan lebih besar dari $\mathrm{R}_{\text {tabel }}$ maka semua kuisioner yang diajukan adalah Valid. Sehingga dapat dilanjutkan dalam penelitian.

b. Uji Reliabilitas

Tabel 3. Uji Reliabilitas

\begin{tabular}{|l|c|c|}
\hline \multicolumn{1}{|c|}{ Variabel } & Cronbach's Alpha & Keterangan \\
\hline Keputusan Pembelian (Y) & 0,731 & Reliabel \\
\hline Produk (X1) & 0,734 & Reliabel \\
\hline Harga (X2) & 0,680 & Reliabel \\
\hline Lokasi (X3) & 0,685 & Reliabel \\
\hline Promosi (X4) & 0,815 & Reliabel \\
\hline
\end{tabular}

Berdasarkan uji relibilitas diatas, Dimana semua variabel memiliki nilai cronbach's Alpha di atas 0,60. Maka seluruh instrument yang digunakan untuk semua variabel tersebut adalah andal dan reliabel.

\section{Uji Asumsi Klasik}

\section{a. Uji Normalitas Data}

Tabel 4. One-Sample Kolmogorov-Smirnov Test

\begin{tabular}{|ll|r|}
\hline & & Unstandardized Residual \\
\hline Normal Parameters & a,b & Mean \\
& Std. Deviation &, 0000000 \\
Most Extreme & Absolute & 1,26006582 \\
Differences & Positive &, 055 \\
Kolmogorov-Smirnov Z & Negative &, 055 \\
Asymp. Sig. (2-tailed) & & -.034 \\
\hline
\end{tabular}

Sumber : olahan data IBM SPSS Versi 21.00

Dari tabel diatas dilihat tingkat sig adalah 0,390 nilainya lebih besar dari tingkat signifikan yang digunakan pada penelitian ini $(\alpha=0,05)$. Dengan demikian dapat disimpulkan bahwa semua variabel tersebut berdistribusi normal.

\section{b. Uji Linearitas}

Tabel 5. ANOVA (Uji Linearitas Produk dengan Keputusan Pembelian)

\begin{tabular}{|lll|r|r|r|r|r|}
\hline & & & $\begin{array}{c}\text { Sum of } \\
\text { Squares }\end{array}$ & Df & $\begin{array}{c}\text { Mean } \\
\text { Square }\end{array}$ & F & Sig. \\
\hline $\begin{array}{l}\text { Keputusan } \\
\text { Pembelian } \\
\text { Produk }\end{array}$ & Between Groups & (Combined) & 99.419 & 6 & 16.570 & 7.884 & .000 \\
& & & & & & \\
& & Linearity & 76.080 & 1 & 76.080 & 36.199 & .000 \\
& & Deviation & 23.339 & 5 & 4.668 & 2.221 & .053 \\
& from & & & & & \\
& Linearity & & & & & \\
& & & 552.747 & 263 & 2.102 & & \\
\hline & & 652.167 & 269 & & & \\
\hline
\end{tabular}


Tabel 6. $\quad$ ANOVA (Uji Linearitas Harga dengan Keputusan Pembelian)

\begin{tabular}{|c|c|c|c|c|c|c|c|}
\hline & & & $\begin{array}{c}\text { Sum of } \\
\text { Squares }\end{array}$ & $\mathrm{Df}$ & $\begin{array}{c}\text { Mean } \\
\text { Square }\end{array}$ & $\mathrm{F}$ & Sig. \\
\hline \multirow{5}{*}{$\begin{array}{l}\text { Keputusan } \\
\text { Pembelian * Harga }\end{array}$} & Between Groups & (Combined) & 177.905 & 6 & 29.651 & 16.443 & .000 \\
\hline & & Linearity & 177.152 & 1 & 177.152 & 98.239 & .000 \\
\hline & & $\begin{array}{l}\text { Deviation } \\
\text { from } \\
\text { Linearity }\end{array}$ & .753 & 5 & .151 & .084 & .995 \\
\hline & Within Groups & & 474.261 & 263 & 1.803 & & \\
\hline & Total & & 652.167 & 269 & & & \\
\hline
\end{tabular}

Sumber : IBM SPSS Versi 21.00

Tabel 7. ANOVA (Uji Linearitas Lokasi dengan Keputusan Pembelian)

\begin{tabular}{|lll|r|r|r|r|r|}
\hline & & & $\begin{array}{c}\text { Sum of } \\
\text { Squares }\end{array}$ & Df & $\begin{array}{c}\text { Mean } \\
\text { Square }\end{array}$ & F & Sig. \\
\hline $\begin{array}{l}\text { Keputusan } \\
\text { Pembelian * }\end{array}$ & Between Groups & (Combined) & 88.357 & 6 & 14.726 & 6.869 & .000 \\
Lokasi & & & & & & \\
& & & & & & & \\
& & Linearity & 81.776 & 1 & 81.776 & 38.146 & .000 \\
& & Deviation & 6.581 & 5 & 1.316 & .614 & .689 \\
& from & & & & & \\
& Linearity & & & & & \\
\cline { 2 - 8 } & Within Groups & & 563.810 & 263 & 2.144 & & \\
\hline
\end{tabular}

Sumber : IBM SPSS Versi 21.00

Tabel 8. $\quad$ ANOVA (Uji Linearitas Promosi dengan Keputusan Pembelian)

\begin{tabular}{|c|c|c|c|c|c|c|c|}
\hline & & & $\begin{array}{c}\text { Sum of } \\
\text { Squares }\end{array}$ & Df & $\begin{array}{l}\text { Mean } \\
\text { Square }\end{array}$ & $\mathrm{F}$ & Sig. \\
\hline \multirow{5}{*}{$\begin{array}{l}\text { Keputusan } \\
\text { Pembelian * } \\
\text { Promosi }\end{array}$} & Between Groups & (Combined) & 107.309 & 6 & 17.885 & 8.633 & .000 \\
\hline & & Linearity & 86.558 & 1 & 86.558 & 41.781 & .000 \\
\hline & & $\begin{array}{l}\text { Deviation } \\
\text { from } \\
\text { Linearity }\end{array}$ & 20.750 & 5 & 4.150 & 2.003 & .079 \\
\hline & Within Groups & & 544.858 & 263 & 2.072 & & \\
\hline & Total & & 652.167 & 269 & & & \\
\hline
\end{tabular}

Sumber : IBM SPSS Versi 21.00

Dari tabel 5, 6, 7 dan 8 diatas dapat dilihat bahwa sig dari deviation from Linearity lebih besar dari 0,05 maka terdapat hubungan yang linear antara variabel bebas terhadap variabel terikat. 


\section{c. Uji Heteroskedastisitas}

Tabel 9. Coefficients ${ }^{\mathrm{a}}$ (Uji Heterokedastisitas)

\begin{tabular}{|l|r|r|r|r|r|}
\hline \multirow{2}{*}{ Model } & \multicolumn{2}{|c|}{$\begin{array}{c}\text { Unstandardized } \\
\text { Coefficients }\end{array}$} & $\begin{array}{l}\text { Standardized } \\
\text { Coefficients }\end{array}$ & \multirow{2}{*}{$\mathrm{t}$} & \multirow{2}{*}{ Sig. } \\
\cline { 2 - 5 } & \multicolumn{1}{c|}{ B } & Std. Error & \multicolumn{1}{c|}{ Beta } & & \\
\hline (Constant) & 2.334 & .548 & & 4.261 & .000 \\
Produk & -.036 & .033 & -.069 & -1.074 & .284 \\
Harga & -.064 & .039 & -.112 & -1.618 & .107 \\
Lokasi & -.055 & .042 & -.098 & -.1304 & .193 \\
Promosi & .040 & 0.38 & .081 & 1.055 & .292 \\
\hline
\end{tabular}

Sumber : IBM SPSS Versi 21.00

Dari tabel diatas dapat dilihat bahwa sig dari Produk, Harga, Lokasi dan Promosi lebih besar dari 0,05 maka dapat disimpulkan tidak terjadi Heterokedastisitas..

\section{d. Uji Multikolinearitas}

Tabel 10. Hasil Uji Multikolinearitas

\begin{tabular}{|l|c|c|}
\hline \multicolumn{1}{|c|}{ Variabel bebas } & Tolerance & VIF \\
\hline Produk (X1) & 0.882 & 1.134 \\
Harga (X2) & 0.770 & 1.299 \\
Lokasi (X3) & 0.644 & 1.553 \\
Promosi (X4) & 0.627 & 1.594 \\
\hline
\end{tabular}

Sumber : Olahan Data IBM SPSS Versi 21.00

Berdasarkan hasil analisis regresi berganda pada tabel $10 \mathrm{di}$ atas, terlihat bahwa variabel bebas dalam penelitian ini yaitu Produk, Harga, Lokasi dan Promosi tidak ada yang kecil dari 0,1 dan nilai VIF tidak ada yang besar dari 10. Nilai tolerance Produk (X1) adalah 0,882, Nilai toleransi Harga (X2) adalah 0,770, Nilai toleransi Lokasi (X3) adalah 0,644, Nilai toleransi Promosi (X4) adalah 0,627 dan hal yang sama juga terjadi pada nilai VIF, dimana nilai VIF Produk (X1) adalah 1,134, nilai VIF Harga (X2) adalah 1,299, nilai VIF Lokasi (X3) adalah 1,553 serta nilai VIF Promosi (X4) adalah 1,594. Dengan demikian di antara variabel independen dinyatakan bebas dari multikolinearitas..

\section{Analisis Regresi Linear Berganda}

Untuk mengetahui pengaruh variabel bebas terhadap Keputusan Pembelian Konsumen pada Fotocopy Sekecamatan Rengat dilakukan pengujian Hipotesis dengan menggunakan beberapa analisis statistik. Dari hasil pengolahan data, maka diperoleh koefisien regresi dan dapat dilihat pada tabel berikut:

Tabel 11 :Koefisien Regresi

\begin{tabular}{|l|r|r|r|r|r|}
\hline \multirow{3}{*}{ Variabel } & \multicolumn{2}{|c|}{$\begin{array}{c}\text { Undstandardized. } \\
\text { Coefficients }\end{array}$} & $\begin{array}{l}\text { standardized } \\
\text { coefficients }\end{array}$ & \multirow{2}{*}{ T } & \multirow{2}{*}{ Sig. } \\
\cline { 2 - 5 } & \multicolumn{1}{|c|}{ B } & Std. Error & \multicolumn{1}{c|}{ Beta } & & \\
\hline (Constant) & 1,473 &, 896 & & 1,645 &, 101 \\
\hline Produk &, 180 &, 055 &, 174 & 3,294 &, 001 \\
\hline Harga &, 426 &, 065 &, 374 & 6,599 &, 000 \\
\hline Lokasi &, 139 &, 069 &, 125 & 2,025 &, 044 \\
\hline Promosi &, 125 &, 062 &, 127 & 2,021 &, 044 \\
\hline
\end{tabular}

Sumber : Data Olahan IBM SPSS Versi 21.0 
Berdasarkan hasil olahan data di atas, maka diperoleh persamaan sebagai berikut :

$$
\begin{aligned}
& \mathrm{Y}=1,473+0,180 \mathrm{X} 1+0,426 \mathrm{X} 2+0,139 \mathrm{X} 3+0,125 \mathrm{X} 4 \\
& \text { Keterangan : } \\
& \mathrm{Y} \quad=\text { Keputusan Pembelian } \\
& \mathrm{a} \quad=\text { Konstanta } \\
& \mathrm{X} 1=\text { Produk } \\
& \mathrm{X} 2=\text { Harga } \\
& \mathrm{X} 3=\text { Lokasi } \\
& \mathrm{X} 4=\text { Promosi }
\end{aligned}
$$

Dari hasil perhitungan dan persamaan analisis statistik koefisien regresi linear berganda di atas, maka dapat diartikan:

a. Nilai konstanta $(a=1,473)$, merupakan konstanta apabila semua nilai variabel Produk, Harga, Lokasi dan Promosi sama dengan 0, maka nilai variabel Keputusan Pembelian (Y) sebesar 1,473.

b. Nilai koefisien Produk $(\mathrm{X} 1=0,180)$. Artinya jika variabel Produk (X1) mengalami/peningkatan 1 satuan dan variabel Harga (X2), Lokasi (X3), Promosi (X4) tetap, maka Keputusan Pembelian akan meningkat sebesar 0,180. Koefisien bernilai positif artinya terjadi hubungan yang positif antara Produk dengan Keputusan Pembelian. Semakin bagus Produk maka akan menaikan Keputusan Pembelian.

c. Nilai koefisien Harga $(X 2=0,426)$. Artinya jika variabel Harga (X2) mengalami/peningkatan 1 satuan dan variabel Produk (X1), Lokasi (X3), Promosi (X4) tetap, maka Keputusan Pembelian akan meningkat sebesar 0,426. Koefisien bernilai positif artinya terjadi hubungan yang positif antara Harga dengan Keputusan Pembelian. Semakin bagus Harga maka akan menaikan Keputusan Pembelian.

d. Nilai koefisien Lokasi $(\mathrm{X} 3=0,139)$. Artinya jika variabel Lokasi (X3) mengalami/peningkatan 1 satuan dan variabel Produk (X1), Harga (X2), Promosi (X4) tetap, maka Keputusan Pembelian akan meningkat sebesar 0,139. Koefisien bernilai positif artinya terjadi hubungan yang positif antara Lokasi dengan Keputusan Pembelian. Semakin bagus Lokasi maka akan menaikan Keputusan Pembelian.

e. Nilai koefisien Promosi $(\mathrm{X} 4=0,125)$. Artinya jika variabel Promosi (X4) mengalami/peningkatan 1 satuan dan variabel Produk (X1), Harga (X2), Lokasi (X3) tetap, maka Keputusan Pembelian akan meningkat sebesar 0,426. Koefisien bernilai positif artinya terjadi hubungan yang positif antara Promosi dengan Keputusan Pembelian. Semakin bagus Promosi maka akan menaikan Keputusan Pembelian.

\section{Koefisien Korelasi Berganda (R)}

Tabel 12: Model Summary Perhitungan Regresi

\begin{tabular}{|l|c|r|r|r|}
\hline Model & $\mathrm{R}$ & R Square & $\begin{array}{c}\text { Adjusted } \mathrm{R} \\
\text { Square }\end{array}$ & $\begin{array}{c}\text { Std. Error Of the } \\
\text { Estimate }\end{array}$ \\
\hline 1 &, $567^{\mathrm{a}}$ &, 345 &, 335 & 1,26954 \\
\hline
\end{tabular}

Sumber : Data Olahan IBM SPSS Versi 21.0

Berdasarkan tabel diatas, dapat diketahui hasil koefisien korelasi berganda (R) yaitu 0,567. Hal ini menunjukkan tingkat hubungan antara seluruh variabel independent terhadap variabel dependent dalam penelitian ini berada dalam kriteria keeratan 
hubungan sedang atau pengaruh sedang. Hal ini berarti keeratan hubungan sedang atau pengaruh sedang.

5. Koefisien Determinasi $\left(\mathbf{R}^{2}\right)$

Tabel 13: $\quad$ Model Summary Perhitungan Regresi

\begin{tabular}{|l|c|r|c|c|}
\hline Model & $\mathrm{R}$ & $\mathrm{R}$ Square & $\begin{array}{c}\text { Adjusted } \mathrm{R} \\
\text { Square }\end{array}$ & $\begin{array}{c}\text { Std. Error Of the } \\
\text { Estimate }\end{array}$ \\
\hline 1 &, $567^{\mathrm{a}}$ &, 345 &, 335 & 1,26954 \\
\hline
\end{tabular}

Sumber : Data Olahan IBM SPSS Versi 21.0

Berdasarkan tabel 13 di atas juga dapat terlihat koefisien determinasi $\left(\mathrm{R}^{2}\right)$. Dari tabel model summary tersebut dapat diketahui nilai R Square adalah 0,345. Jadi, sumbangan pengaruh dari variabel independent yaitu $34,5 \%$, sedangkan sisanya sebesar $65,5 \%$ dipengaruhi oleh variabel lain yang tidak diteliti dalam penelitian ini.

\section{Uji Parsial}

$$
\begin{aligned}
& \text { Df } \quad=\quad \alpha / 2 ; \mathrm{n}-\mathrm{k} \\
& =0,05 / 2 ; 270-5 \\
& =0,025 ; 265 \\
& =\quad 1,968956
\end{aligned}
$$

Tabel 14 : Uji Regresi secara Parsial

\begin{tabular}{|l|r|r|r|r|r|}
\hline \multirow{2}{*}{ Variabel } & \multicolumn{2}{|c|}{$\begin{array}{c}\text { Undstandardized. } \\
\text { Coefficients }\end{array}$} & $\begin{array}{c}\text { standardized } \\
\text { coefficients }\end{array}$ & \multirow{2}{*}{ T } & \multirow{2}{*}{ Sig. } \\
\cline { 2 - 4 } & \multicolumn{1}{|c|}{ B } & Std. Error & \multicolumn{1}{c|}{ Beta } & & \\
\hline (Constant) & 1,473 &, 896 & & 1,645 &, 101 \\
\hline Produk &, 180 &, 055 &, 174 & 3,294 &, 001 \\
\hline Harga &, 426 &, 065 &, 374 & 6,599 &, 000 \\
\hline Lokasi &, 139 &, 069 &, 125 & 2,025 &, 044 \\
\hline Promosi &, 125 &, 062 &, 127 & 2,021 &, 044 \\
\hline
\end{tabular}

Sumber : Data Olahan IBM SPSS Versi 21.0

\section{a. Pengaruh Produk Terhadap Keputusan Pembelian}

Untuk variabel produk, diperoleh $t_{\text {hitung }} 3,294>t_{\text {tabel }} 1,968956$ atau Sig $0,001<\alpha$ 0,05. Berdasarkan kriteria pengujian data dapat diketahui bahwa $\mathrm{H}_{0}$ ditolak dan $\mathrm{H}_{\mathrm{a}}$ diterima, artinya produk secara parsial berpengaruh terhadap keputusan pembelian.

\section{b. Pengaruh Harga Terhadap Keputusan Pembelian}

Untuk variabel harga, diperoleh $t_{\text {hitung }} 6,599>t_{\text {tabel }} 1,968956$ atau Sig $0,000<\alpha$ 0,05. Berdasarkan kriteria pengujian data dapat diketahui bahwa $\mathrm{H}_{0}$ ditolak dan $\mathrm{H}_{\mathrm{a}}$ diterima, artinya dana harga secara parsial berpengaruh terhadap keputusan pembelian.

\section{c. Pengaruh Lokasi Terhadap Keputusan Pembelian}

Untuk variabel lokasi, diperoleh $t_{\text {hitung }} 2,025>t_{\text {tabel }} 1,968956$ atau Sig $0,044<\alpha$ 0,05. Berdasarkan kriteria pengujian data dapat diketahui bahwa $\mathrm{H}_{0}$ ditolak dan $\mathrm{H}_{\mathrm{a}}$ diterima, artinya lokasi secara parsial berpengaruh terhadap keputusan pembelian.

\section{d. Pengaruh Promosi Terhadap Keputusan Pembelian}

Untuk variabel Promosi, diperoleh $t_{\text {hitung }} 2,021>t_{\text {tabel }} 1,968956$ atau Sig 0,044 $<\alpha$ 0,05. Berdasarkan kriteria pengujian data dapat diketahui bahwa $\mathrm{H}_{0}$ ditolak dan $\mathrm{H}_{\mathrm{a}}$ diterima, artinya promosi secara parsial berpengaruh terhadap keputusan pembelian.

Jadi dalam penelitian ini, semua variabel independen (Produk, Harga, Lokasi dan Promosi) secara parsial berpengaruh signifikan terhadap variabel dependen (Keputusan Pembelian). 


\section{Uji Simultan}

Hasil perhitungan $\mathrm{F}$ hitung dengan program IBM SPSS Versi 21.0 dan perbandingan dengan $\mathrm{F}$ tabel adalah sebagai berikut.

Tabel 15: Tabel ANOVA

\begin{tabular}{|cl|c|c|c|c|l|}
\hline & Model & $\begin{array}{c}\text { Sun Of } \\
\text { Squares }\end{array}$ & Df & $\begin{array}{c}\text { Mean } \\
\text { Square }\end{array}$ & F & Sig. \\
\hline 1 & Regression & 225.058 & 2 & 56.264 & 34.909 & $.000^{\mathrm{b}}$ \\
& Residual & 427.109 & 265 & 1.612 & & \\
& Total & 652.167 & 269 & & & \\
\hline
\end{tabular}

Sumber : Data Olahan IBM SPSS Versi 21.0

Dari tabel hasil perhitungan di atas, dapat diketahui bahwa $\mathrm{F}$ hitung sebesar 34,909 dan $\mathrm{F}$ tabel dengan taraf signifikan 5\%.

$$
\begin{aligned}
& \text { df } 1=k-1=5-1=4 \\
& \text { df } 2=n-k=270-5=265 \\
& \text { maka F tabel dari df } 1 ; \text { df } 2=4 ; 265=2,405708
\end{aligned}
$$

Diperoleh nilai $F_{\text {hitung }} 34,909>F_{\text {tabel }} 2,405708$ atau $\operatorname{Sig} 0,000<\alpha 0,05$, maka berdasarkan kriteria pengujian data dapat diketahui bahwa $\mathrm{H}_{0}$ ditolak dan $\mathrm{H}_{\mathrm{a}}$ diterima, artinya Produk, Harga, Lokasi dan Promosi secara bersama-sama (simultan) berpengaruh terhadap Keputusan Pembelian.

\section{Pembahasan}

\section{a. Pengaruh Produk terhadap Keputusan Pembelian}

Diperoleh nilai $t_{\text {hitung }} 3,294>t_{\text {tabel }} 1,968956$ dengan nilai Sig $0,001<\alpha 0,05$, berdasarkan kriteria pengujian data dapat diketahui bahwa $\mathrm{H}_{0}$ ditolak dan $\mathrm{H}_{\mathrm{a}}$ diterima, artinya produk secara parsial berpengaruh signifikan terhadap Keputusan Pembelian Konsumen pada Fotocopy Sekecamatan Rengat. Hasil uji penelitian yang dilakukan sejalan dengan penelitian yang dilakukan oleh Supriyatno, Hasiolan, \& Warso (2014) yang dimana judul penelitiannya pengaruh produk, harga dan promosi terhadap keputusan konsumen dalam membeli rumah pada Perumahan Bukit Semarang Baru (BSB) City di Semarang. Hasil penelitian menunjukan produk secara parsial berpengaruh terhadap keputusan pembelian.

Selain itu penelitian yang dilakukan peneliti juga sejalan dengan penelitian yang dilakukan oleh Zulaicha \& Irawati (2016) dengan judul penelitiannya yaitu pengaruh produk dan harga terhadap keputusan pembelian konsumen di morning bakery Batam. Hasil penelitian menunjukan produk secara parsial berpengaruh terhadap keputusan pembelian.

Penelitian yang juga dilakukan oleh Hermanto (2018) yang berjudul Pengaruh Produk dan Kepuasan Konsumen terhadap Keputusan Pembelian pada PT. Alfa Scorfii Pematang Reba. Hasil penelitian menunjukan bahwa produk secara parsial berpengaruh terhadap keputusan pembelian. Dapat ditarik kesimpulan bahwa dari tiga penelitian yang dilakukan oleh peneliti sebelumnya bahwa produk secara parsial berpengaruh signifikan terhadap keputusan pembelian dan sejalan juga dengan penelitian yang dilakukan peneliti.

Maka dari itu, Produk yang dijual oleh pelaku usaha harus lebih komplit dengan segala varian produk yang bisa ditemukan oleh konsumen dan konsumen tidak akan berpindah ke tempat yang lain. 


\section{b. Pengaruh Harga Terhadap Keputusan Pembelian}

Diperoleh nilai $t_{\text {hitung }} 6,599>t_{\text {tabel }} 1,968956$ dengan nilai Sig $0,000<\alpha 0,05$, berdasarkan kriteria pengujian data dapat diketahui bahwa $\mathrm{H}_{0}$ ditolak dan $\mathrm{H}_{\mathrm{a}}$ diterima, artinya Harga secara parsial berpengaruh signifikan terhadap Keputusan Pembelian Konsumen pada Fotocopy Sekecamatan Rengat. Penelitian yang dilakukan peneliti juga sejalan dengan penelitian oleh Setiawati \& Tyas (2015) yang berjudul pengaruh harga dan citra merek terhadap keputusan pembelian televisi samsung di perumahan villa grand tomang tangerang. Hasil penelitian menunjukan harga secara parsial berpengaruh terhadap keputusan pembelian, hal ini sesuai dengan penelitian yang dilakukan peneliti.

Selain itu penelitian yang dilakukan oleh Hermanto (2018a) yang berjudul pengaruh persaingan dan harga terhadap keputusan pembelian sepeda motor pada CV. Greentech Belilas Kabupaten Indragiri Hulu, hasil penelitian menunjukan harga secara parsial berpengaruh signifikan terhadap keputusan pembelian.

Hasil hipotesis penelitian ini juga sesuai dengan Sari \& Nuvriasari (2018) dengan judul pengaruh citra merek, kualitas produk dan harga terhadap keputusan pembelian produk merek eiger, hasil penelitian menunjukan harga secara parsial berpengaruh terhadap keputusan pembelian.

Dapat ditarik kesimpulan bahwa dari tiga penelitian yang dilakukan oleh peneliti sebelumnya bahwa harga secara parsial berpengaruh signifikan terhadap keputusan pembelian dan sejalan juga dengan penelitian yang dilakukan peneliti. Dalam hal ini dapat dikatakan harga merupakan factor yang menentukan seseorang juga dalam membeli produk yang dijual oleh pelaku usaha. Sebagai pelaku usaha dalam menetapkan harga sebaiknya menyesuiakan harga produk sesuai dengan pasaran agar bisa bersaing dengan pelaku usaha lain. Sebagai pelaku usaha didalam pemberian harga, juga mampu memberikan potongan harga kepada konsumen yang berbelanja, sehingga mereka akan kembali lagi untuk berbelanja.

\section{c. Pengaruh Lokasi Terhadap Keputusan Pembelian}

Diperoleh nilai $t_{\text {hitung }} 2,025>t_{\text {tabel }} 1,968956$ dengan nilai Sig $0,044<\alpha 0,05$, berdasarkan kriteria pengujian data dapat diketahui bahwa $\mathrm{H}_{0}$ ditolak dan $\mathrm{H}_{\mathrm{a}}$ diterima, artinya Lokasi secara parsial berpengaruh signifikan terhadap Keputusan Pembelian Konsumen pada Fotocopy Sekecamatan Rengat. Penelitian yang dilakukan peneliti juga sejalan dengan penelitian oleh Puspitasari, Eka, \& Nailis (2018) yang berjudul pengaruh Lokasi dan Citra merek terhadap Keputusan Pembelian Konsumen (Studi Kasus pada Konsumen KFC Dermaga Point Palembang), hasil penelitian menunjukan lokasi secara parsial berpengaruh signifikan terhadap keputusan pembelian. Hal ini sejalan dengan penelitian yang dilakukan peneliti.

Selain itu peneliti juga sejalan penelitian yang dilakukan oleh Riandika \& Arifin (2017) yang berjudul pengaruh lokasi, harga dan keragaman produk terhadap keputusan pembelian di Mall Dinoyo City, hasil penelitian menunjukan lokasi secara parsial berpengaruh terhadap keputusan pembelian.

Selain itu peneliti lain juga melakukan penelitian yang terkait dengan variabel yang diteliti peneliti, yang dilakukan oleh Tobing \& Sihombing (2016) yang berjudul pengaruh lokasi, keragaman produk dan harga terhadap keputusan pembelian (studi pada Carrefour Citra Garden Medan), hasil penelitian menunjukan lokasi secara parsial berpengaruh terhadap keputusan pembelian.

Dapat ditarik kesimpulan dari ketiga hasil penelitian yang dilakukan penelitian lain sebelum peneliti melakukan penelitian tentang variabel lokasi dan keputusan pembelian, menyatakan bahwa lokasi secara parsial berpengaruh signifikan terhadap keputusan pembelian. Hal ini, sejalan dengan hasil penelitian yang telah dibuat dengan peneliti. Dengan demikian lokasi merupakan yang harus diperhatikan oleh pelaku bisnis untuk 
mendirikan usaha, pelaku bisnis harus mampu mendirikan usaha potocopy didekat sekolah, perkantoran dan pusat keramaian.

\section{d. Pengaruh Promosi Terhadap Keputusan Pembelian}

Diperoleh nilai $t_{\text {hitung }} 2,021>t_{\text {tabel }} 1,968956$ dengan nilai Sig 0,044 $<\alpha 0,05$, berdasarkan kriteria pengujian data dapat diketahui bahwa $\mathrm{H}_{0}$ ditolak dan $\mathrm{H}_{\mathrm{a}}$ diterima, artinya Promosi secara parsial berpengaruh signifikan terhadap Keputusan Pembelian Konsumen pada Fotocopy Sekecamatan Rengat. Penelitian yang dilakukan peneliti juga sejalan dengan penelitian oleh M. Setiawati \& Lumbantobing (2017) yang berjudul pengaruh Promosi dan Kemasan terhadap Keputusan Pembelian Produk Chitato yang dimediasi olah Brand Awareness, hasil penelitian menunjukan promosi secara parsial berpengaruh terhadap keputusan pembelian. Hal ini sejalan dengan penelitian yang dilakukan peneliti, bahwa promosi secara parsial berpengaruh terhadap keputusan pembelian.

Peneliti lain juga melakukan penelitian yang berkaitan tentang promosi dan keputusan pembelian, yang diteliti oleh Achidah, Warso, \& Hasiolan (2016) yang berjudul pengaruh promosi, harga dan desain terhadap keputusan pembelian sepeda motor Mio GT (studi empiris pada produk Yamaha Mio GT di Weleri-Kendal), hasil penelitian menunjukan promosi secara parsial berpengaruh terhadap keputusan pembelian.

Selain itu peneliti lain juga melakukan penelitian yang berkaitan dengan promosi dan keputusan pembelian yang diteliti oleh Permana (2017) yang berjudul pengaruh promosi terhadap keputusan pembelian produk lantai kayu dan pintu PT. Piji di Jawa Timur, hasil penelitian menunjukan promosi secara parsial berpengaruh terhadap keputusan pembelian.

Dari ketiga penelitian yang dilakukan peneliti lain sebelum peneliti, dimana hasil penelitian sejalan dengan penelitian yang dilakukan peneliti yaitu promosi secara parsial berpengaruh signifikan terhadap keputusan pembelian. Maka dari itu promosi penting dilakukan oleh pelaku bisnis untuk memperkenalkan usaha yang dijalankannya agar produk yang dijualnya bisa diketahui oleh pembeli, promosi yang dilakukan bisa menggunakan media online seperti Facebook, Twiter, IG, WA dan media sosial lainnya.

\section{PENUTUP}

\section{Kesimpulan}

a. Faktor-faktor yang mempengaruhi keputusan pembelian adalah Produk, Harga, Lokasi dan Promosi, dimana hasil penelitian secara simultan menunjukan, Produk, Harga, Lokasi dan Promosi secara simultan berpengaruh signifikan terhadap Keputusan Pembelian.

b. Hasil penelitian secara parsial bahwa keempat variabel bebas yaitu Produk, Harga, Lokasi dan Promosi berpengaruh signifikan terhadap Keputusan Pembelian. Dari keempat variabel tersebut harga merupakan variabel yang berpengaruh dominan, selanjut diiukti oleh Produk, Lokasi dan Promosi

c. Hasil Koefisien korelasi berganda menunjukkan tingkat hubungan antara seluruh variabel independent (Produk, Harga, Lokasi dan Promosi) terhadap variabel dependent (Keputusan Pembelian) dalam penelitian ini berada dalam kriteria keeratan hubungan sedang. Hal ini berarti keeratan hubungan sedang atau pengaruh sedang. Hasil koeefesien deteminasi menunjukan bahwa sumbangan kontribusi variabel Produk, Harga, Lokasi dan Promosi secara bersama - sama terhadap variabel Keputusan Pembelian sebesar 34,5\% dan sisanya dipengaruhi oleh variabel lain yang tidak diteliti dalam penelitian ini. 


\section{Saran}

a. Sebaik sebagai pelaku bisnis usaha fotocopy sekecamatan Rengat dapat membentuk perserikatan Fotocopy seKecamatan Rengat, agar sesama pelaku bisnis bisa menyeragamkan harga jual dari barang, maka akan terciptanya persaingan yang sehat.

b. Pelaku bisnis satu dengan yang pelaku bisnis lainnya bisa melakukan kerja sama dan saling membantu didalam bisnis.

c. Pelaku bisnis dalam menentukan lokasi usaha, harus memperhatikan parkiran untuk konsumen dalam berbelanja, selain produk yang dijual harus banyak dan varian berbeda dengan harga yang sewajar bila dibutuhkan konsumen.

\section{REFERENCE}

Buku

Assauri, Sofjan. 2013. Manajemen Pemasaran. Rajawali Pers. Jakarta.

Ginting, Nembah F Hartimbul. 2011. Manajemen Pemasaran. CV. Yrama Widya. Bandung.

Mursid, M. 2010. Manajemen Pemasaran. PT. Bumi Aksara. Jakarta.

Simamora, Bilson. 2008. Panduan Riset Perilaku Konsumen. PT. Gramedia Pustaka Utama. Jakarta.

Sunyoto, Danang. 2014. Dasar - Dasar Manajemen Pemasaran. CAPS. Yogyakarta.

Winarno, Surakhmad. 2004. Pengantar Penelitian Ilmiah, Dasar, Metode, dan Teknik. Tarsito. Bandung

\section{Jurnal}

Achidah, N., Warso, M. M., \& Hasiolan, L. B. (2016). PENGARUH PROMOSI, HARGA, DAN DESAIN TERHADAP KEPUTUSAN PEMBELIAN SEPEDA MOTOR MIO GT (Study Empiris Pada Produk Yamaha Mio GT Di Weleri-Kendal). Journal of Management, 2(2).

Hermanto, H. (2018a). Pengaruh Persaingan Dan Harga Terhadap Keputusan Pembelian Sepeda Motor Pada Cv. Greentech Belilas Kabupaten Indragiri Hulu. Jurnal Manajemen Dan Bisnis, 7(2), 54-63. https://doi.org/10.34006/jmbi.v7i2.51

Hermanto, H. (2018b). Pengaruh Produk Dan Kepuasan Konsumen Terhadap Keputusan Pembelian Pada Pt. Alfa Scorpii Pematang Reba. Jurnal Manajemen Dan Bisnis, 7(4), 106-113. https://doi.org/10.34006/jmb.v7i4.26

Permana, D. I. (2017). Pengaruh Promosi Terhadap Keputusan Menabung Nasabah. Jurnal Manajemen Dan Start-Up Bisnis, 2(1), 116-223.

Puspitasari, P., Eka, D., \& Nailis, W. (2018). PENGARUH LOKASI DAN CITRA MEREK TERHADAP KEPUTUSAN PEMBELIAN KONSUMEN (Studi Kasus Pada Konsumen KFC Dermaga Point Palembang). Jembatan, 15(1), 23-32. https://doi.org/10.29259/jmbt.v15i1.5881

Riandika, R. N., \& Arifin, R. (2017). PENGARUH LOKASI, HARGA DAN KERGAMAN PRODUK TERHADAP KEPUTUSAN PEMBELIAN DI MALL DINOYO CITY (Studi Kasus Pada Konsumen Mall Dinoyo City). E - Jurnal Riset Manajemen, 5064.

Sari, D. P., \& Nuvriasari, A. (2018). Pengaruh Citra Merek, Kualitas Produk Dan Harga Terhadap Keputusan Pembelian Produk Merek Eiger (Kajian Pada Mahasiswa Universitas Mercu Buana Yogyakarta). Jurnal Penelitan Ekonomi Dan Bisnis, 3(2), 73-83. https://doi.org/10.33633/jpeb.v3i2.2298 
Setiawati, E., \& Tyas, A. A. W. P. (2015). PENGARUH HARGA DAN CITRA MEREK TERHADAP KEPUTUSAN PEMBELI. PROSIDING SEMINAR NASIONAL MULTI DISIPLIN ILMU \& CALL FOR PAPERS UNISBANK (SENDI_U) Kajian Multi Disiplin Ilmu Untuk Mewujudkan Poros Maritim Dalam Pembangunan Ekonomi Berbasis Kesejahteraan Rakyat, 978-979.

Setiawati, M., \& Lumbantobing, R. (2017). PENGARUH PROMOSI DAN KEMASAN TERHADAP KEPUTUSAN PEMBELIAN PRODUK CHITATO YANG DIMEDIASI OLEH BRAND AWARENESS. KOMPETENSI - JURNAL MANAJEMEN BISNIS, 12(01), 75-88. Retrieved from http://ejournal.ukrida.ac.id/ojs/index.php/MB/article/view/1361/1495

Supriyatno, K., Hasiolan, L. B., \& Warso, M. M. (2014). PENGARUH PRODUK, HARGA DAN PROMOSI TERHADAP KEPUTUSAN KONSUMEN DALAM MEMBELI RUMAH PADA PERUMAHAN BUKIT SEMARANG BARU (BSB) CITY DI SEMARANG. Jurnal Skripsi Ekonomi Manajemen, 1-16. https://doi.org/10.1080/10875549.2014.999970

Tobing, F. M., \& Sihombing, D. (2016). PENGARUH LOKASI, KERAGAMAN PRODUK DAN HARGA TERHADAP KEPUTUSAN PEMBELIAN (Studi Pada Carrefour Citra Garden Medan). Jurnal Plans Penelitian Ilmu Manajemen Dan Bisnis, 11(2), 149-156.

Zulaicha, S., \& Irawati, R. (2016). Pengaruh Produk Dan Harga Terhadap Keputusan Pembelian Konsumen Di Morning Bakery Batam. Inovbiz: Jurnal Inovasi Bisnis, 4(2), 123. https://doi.org/10.35314/inovbiz.v4i2.76 